\title{
A Mind Map Teaching Mode for Sports Anatomy based on 3DBody
}

$\underline{\text { https://doi.org/10.3991/ijet.v14i10.10776 }}$

\author{
Yujia Ren \\ Hunan First Normal University, Changsha, China \\ renyujia@163.com \\ Xia Jiang \\ Wuhan Sports University, Wuhan, China
}

\begin{abstract}
With the popularization of various new educational concepts, selecting appropriate teaching auxiliary methods according to the course content improves the effectiveness of teaching. Accordingly, this study explores the application of mind map teaching methods in the course, Sports Anatomy. It also incorporates the 3D structure exhibition function of the 3DBody software in teaching anatomical research to establish the teaching mode reform. Moreover, the traditional multimedia anatomy teaching method was employed, and the effects of both teaching modes were compared. Results show that teaching Sports Anatomy using the 3DBody based on mind mapping evidently improves students' learning interest and stimulates their initiative for independent study on Sports Anatomy teaching. In addition, this teaching mode can assist students in constructing a knowledge chain from a local to a global standpoint and promote their creative and logical thinking. Compared with the traditional teaching mode, mind map teaching can improve the quality of teaching. Therefore, it is an effective method of reforming the teaching mode in courses, such as Sports Anatomy.
\end{abstract}

Keywords-3DBody; Mind map; Sports Anatomy

\section{$1 \quad$ Introduction}

Information technology has extensive applications in various industries. Specifically, the application of visualization and experience techniques facilitates information exchange among individuals. In teaching application, such effect significantly promotes the improvement of teaching methods and can help teachers and students achieve all-around utilization and communication of educational resources from software to hardware. Teachers transmit information in class, and students fully apply information technology to enable smooth acquisition of knowledge. Thus, reforming through all kinds of advanced information techniques and classroom teaching modes is an important subject for current education system research. One major direction for teaching mode research is selecting appropriate teaching means and techniques ac- 
cording to the features of each course and displaying knowledge in a mode that is beneficial to students' understanding and innovation.

Teaching defects brought by traditional teaching habits are evident in the existing research on human learning behavior. Rote memorization cannot genuinely improve students' creative ability. The current pursuit of quality-oriented education triggers the continuous development of efficient learning methods. The sustainable application of targeted learning ability cultivation methods based on brain learning thinking modes in school education has become the target of educational circles for scientific teaching and quality-oriented education [1]. The mind map method, an advanced teaching technique in the educational field, has recently won extensive attention in the research field [2]. Sports Anatomy is an important foundation course in medical studies. It aims to grant students a clear cognizance of anatomical structures and the functions of each structure, reserve basic knowledge for clinical work, and motivate their enthusiasm for anatomical exploration. However, with the increasing demand for teaching resources and limited specimen resources applied in teaching medicine, the field of anatomy is confronted with certain predicaments: teaching resources are insufficient; more attention is given to theoretical teaching than practical teaching; and students have no learning interest. With the rapid development of computer technology, the 3DBody model software based on 3D display technology conforms to the demand of anatomical teaching. This software has been promoted vigorously and is expected to solve the difficulties faced by the field of anatomy [3].

Sports Anatomy was chosen as the sample course. Visualization information technology and the mind map method guiding learning behaviors were adopted to explore a new teaching mode for this course. This new method aims to change the lowefficiency learning state in the traditional teaching process, probe into a scientific and efficient teaching mode suitable for the course, and cultivate other sports medicine talents with innovation ability for society.

\section{State of the Art}

The mind map is a revolutionary mind tool first proposed by British scholar Tony Buzan [4]. Later, people started applying this tool in the educational field. Mind mapping employs the best pictures and texts to transform dull teaching information into colorful and appealing teaching aids, which can help students remember and understand the subject matter and further promote their divergent thinking. The effect of the mind map teaching method in abstract teaching, such as that in the medical field, is particularly evident. $\mathrm{Hu}$ [5] obtained favorable results by applying the mind map teaching method to replace the traditional teaching method. Compared with rote memorization, mind mapping is more superior as it can immensely stimulate students' learning interest and improve learning efficiency. Kalyanasundaram et al. [6] conducted applied research on information retrieval course learning of medical college students and found that the mind map method could significantly facilitate students in mastering medical information and rapidly corresponding retrieved knowledge. This finding indicates that the mind map teaching method helps students organize concepts 
rapidly for abstract courses with high memory requirement. Woradechjumroen et al. [7] applied the mind map in the course, System Dynamics. In the experiment, each student was assigned to design a personal mind map after class and learned the overall case of each chapter from the adviser. The results showed that mind mapping improved academic performance and significantly reduced review time.

Various kinds of advanced image processing software can turn abstract medical knowledge into concrete materials to help students understand and remember information visually. The 3DBody software is a digital model software that can display 3D human organ structures from multiple angles. It covers nine systems of the human body, including systematic, topographic, and sectional anatomies. Ren et al. [8] indicated that applying the 3DBody software in the classroom could significantly enhance students' enthusiasm for learning human anatomy. Researchers [9-10] adopted the 3DBody software to study anatomy and indicated that such software could solve the problems pertaining to the traditional wall map of anatomy, such as poor third dimension, model distortion, and specimen source deficiency. The software also provides a good opportunity for anatomical practice. Sports Anatomy is an important foundation course in the study of medicine, in which students study the structures and functions of the normal human body from a morphological perspective. This course has strong visuality and practicality. The traditional experiment teaching method of human anatomy mostly consists of the following steps. First, the teacher demonstrates the specimen, which students observe and discuss in groups. Then, the teacher tutors them. In such teaching mode, students have little opportunity to make contact with the specimen. They learn many theories and break away from practice. Alternatively, the practical operation is neglected owing to the shortage of experimental facilities. Students receive unsatisfactory tuition, and their learning interest is not motivated [11]. The most important function of the 3DBody anatomy software is its capacity to replace traditional teaching resources of human anatomy, such as wall map, models, and specimen. In addition, it can show good third-dimension case models and enhance the students' tactile and operational experience. Therefore, completely developing the application of the 3DBody anatomy software is especially necessary in anatomy teaching.

The mind map tool was innovatively applied to conclude and deduce scattered medical anatomy knowledge in this study. Meanwhile, the 3DBody anatomy software was used to compensate for the limitations of traditional anatomy resources, thereby enabling the new teaching mode to break through the plight of the poor effects of traditional anatomy teaching. This process will certainly be one development direction for anatomy teaching reform under the new developments in information technology. 


\section{Specific Mode of 3DBody Sports Anatomy Teaching Based on Mind Map}

\subsection{Application mode of mind map teaching method}

As a systematic thinking tool, the mind map has profound evident advantages in knowledge system connection, conclusion, and deduction. This method boosts learning efficiency by collating key knowledge points. In addition, it can effectively connect new and old knowledge to create a new knowledge system. The mind map adopts colors and shapes to process knowledge into the learners' right brain through a vivid and concrete framework. This method continuously stimulates association and innovation awareness of the brain. In addition, learners digest scattered knowledge and resources, create a new system, and improve learning innovation ability [12].

In view of the above guiding thought, the mind map teaching method typically adopts rich and vivid colors and patterns and focuses on a theme for divergence. It fully mines the information factors involved and forms the thinking maps with various shapes. Fig. 1 (part of screenshot of the original mind map) shows the mind map of the motor system. The information is collated from bone, skeletal muscle, and bony union to allow for a clear, concise, and easy-to-understand content of each subject.

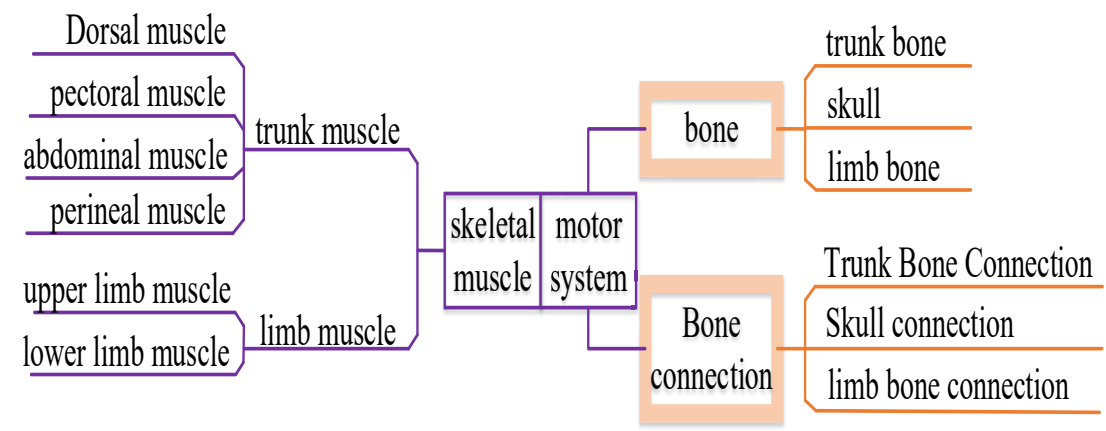

Fig. 1. Mind map of motor system in anatomy

In the field of anatomy, the mind map can clearly collate the sequence and connection of each knowledge point as shown in Fig. 2 (part of screenshot of the original mind map). The map is vivid, visual, clear, and beautiful, and can easily stimulate students' learning interest and initiative — a typical effect of mind map application in anatomy. 


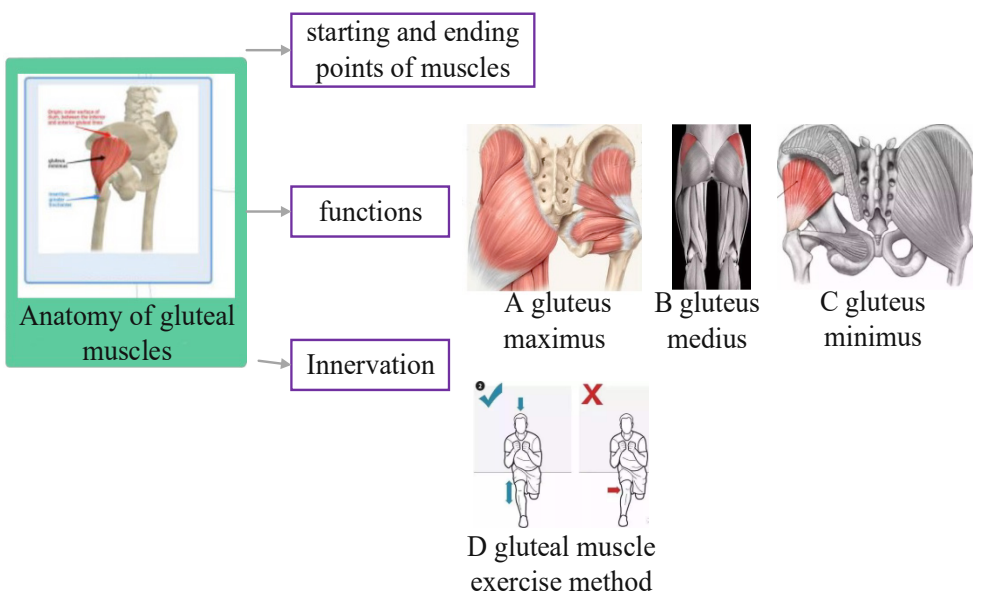

Fig. 2. Screenshot of mind map of "gluteus minimus anatomy" learning

\subsection{Teaching application mode of 3DBody software}

The 3DBody anatomy software based on the 3D concept is designed for male and female body structure systems, including over 5,000 important body structures and covering position and form changes of each body structure in all kinds of motions. Current 3DBody software, such as 3DBodyv.7.0, can note every anatomical term; mark bone marking patterns; form muscle motion animation; and list acupuncture points, starting points, and sectional anatomy information. Hence, the software possesses a complete teaching function of human anatomy. In addition, it can provide pictures with $3 \times 360^{\circ}$ rotation. Sports Anatomy aims to study the effects of various sports on morphological structure, growth, and development of the human body based on human anatomy. Thus, the 3DBody software is especially suitable for anatomy teaching. Using it can deliberately display or hide any muscle, blood vessel, and organ. It can display vivid, visual, and deep sensual experience to students through free connections and combinations. Moreover, it can help students treat the mouse as a scalpel to decompose and restore human body structure, thereby achieving anatomy and recovery layer by layer. Accordingly, students' autonomous learning interest and learning ability can improve quickly. Developing and extensively applying other functions of the $3 \mathrm{DBody}$ software will strengthen the latter while simultaneously improving the professionalism and efficiency of anatomy teaching. It will almost perfectly resolve a series of problems faced by traditional anatomy teaching, such as anatomy teaching resource deficiency.

\subsection{Mind map teaching mode design for Sports Anatomy based on 3DBody software}

When the mind map is applied in anatomy teaching, key knowledge points of each chapter can be collated. Understanding, collating, organizing, and reconstructing 
relevant knowledge in advance are necessary in creating a mind map. Students must grasp the knowledge content of anatomy by independently reading and looking up materials and then making the appropriate mind maps. Thus, teaching students the method of establishing the mind map is required first to design the mind map and apply it in anatomy teaching. Consequently, the author introduced the course objective, requirement, and anatomy's basic theoretical system to the students of Sports Anatomy. The author also pushed the mind map learning method to facilitate the students' understanding of the 3DBody anatomy software 3DBody v7.0 (mobile app).

First, the teacher should establish anatomy maps, anatomical structural functions, nerve anatomy by a scalpel, and other relevant content files involved in each chapter. Then, the software should be applied in theory class combined with PPT. Before applying the software, the teacher should send the new course content of each chapter to the students in advance for them to utilize the visual expression advantage of $3 \mathrm{D}$ pictures and knowledge conclusion advantage of mind map. These visuals will help the students understand and remember as many new knowledge points as possible according to 3D anatomy pictures and new knowledge from the textbook while studying each chapter. During the design of the teaching content for the subsequent chapters, the powerful 3D display model of the 3DBody software can be utilized to show realtime and dynamic observations of relevant content based on a combination of multimedia teaching. At the same time, the students are required to write text descriptions and analyze the lesson to improve their understanding of the learning content. The teacher should guide the students in fully maximizing the mind map learning tool to conclude and deduce relevant content and draw a mind map of each chapter. In the subsequent review or exercise link, the students should combine relevant assignments or tasks to consolidate the content further via mobile phones or computers. Accordingly, the students can have a firm grasp of key and difficult knowledge points in every chapter. In this study, the students in the experimental class were divided into groups, and each group learned in accordance with the mind map based on the 3DBody and other review materials. For example, they could position the locations according to the teaching content and mutually design strength and stretching actions. Students were encouraged to exchange, discuss, and comment. The information from this chapter was further collated and concluded for further review. Four class periods were used for the mode application and anatomy experimental teaching, two class periods per week, and two weeks in total. Fig. 3 shows the screenshot of a 3DBodybased motion teaching plan for the chapter on the cricothyroid membrane (Site A where the arrow points in the figure) designed by the author. The teaching plan conveniently displays the laryngeal structure and the structure around it as well as the cartilage and membrane tissues of the laryngeal structure in the classroom teaching link. Fig. 4 represents the mind map of the chapter. This mind map collects all key points of the chapter and is displayed in the teaching link.

Fig. 5 shows the screenshot of a 3DBody-based teaching plan for the chapter on the urinary system. Fig. 6 displays the mind map of this chapter. 


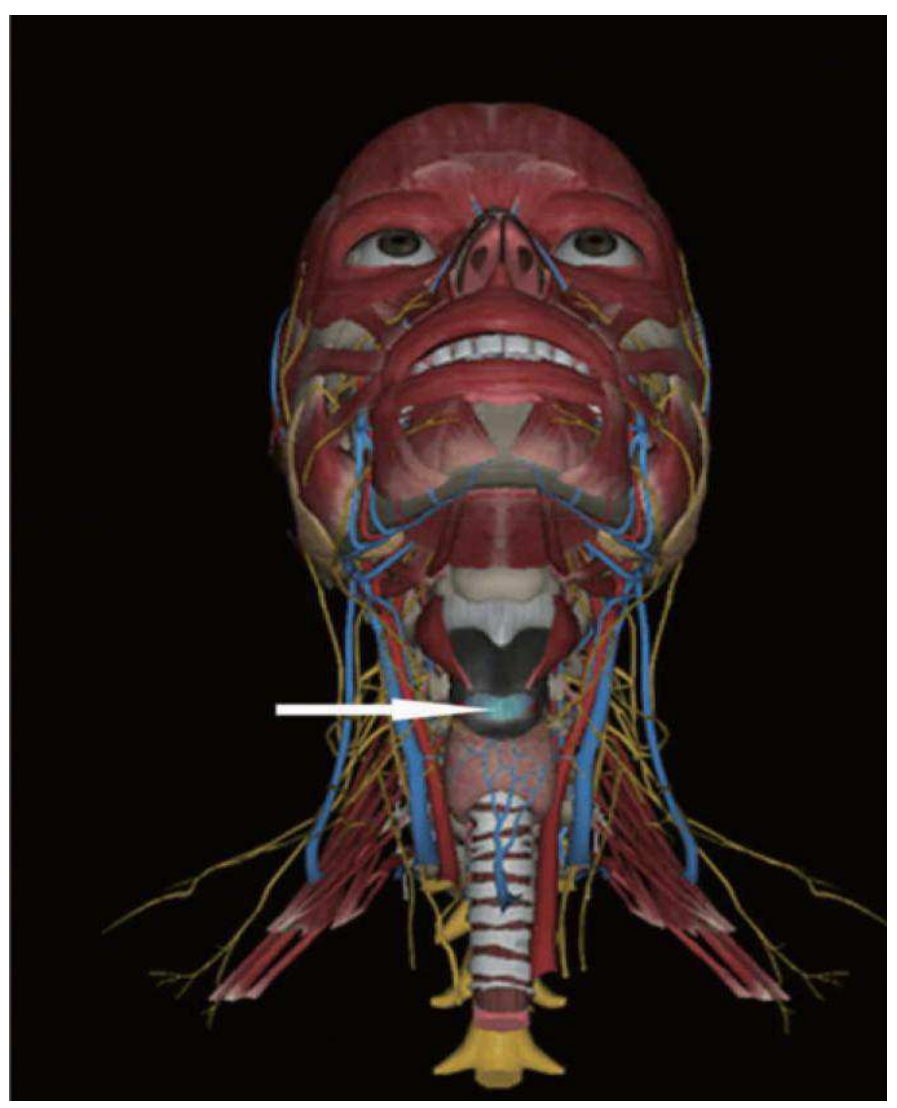

Fig. 3. Screenshot of the 3DBody-based motion teaching plan for cricothyroid membrane (Site A where the arrow points in the figure)

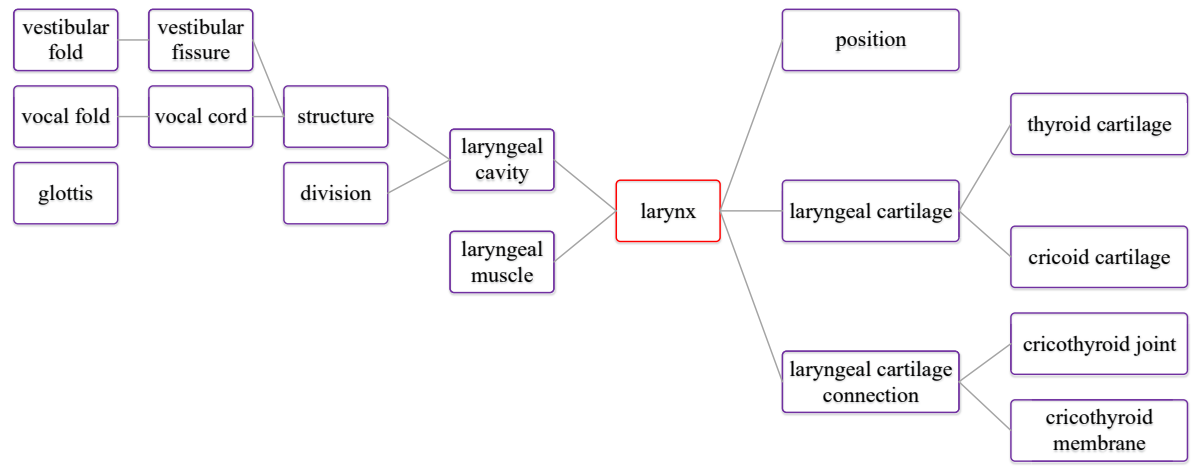

Fig. 4. Mind map of larynx chapter 


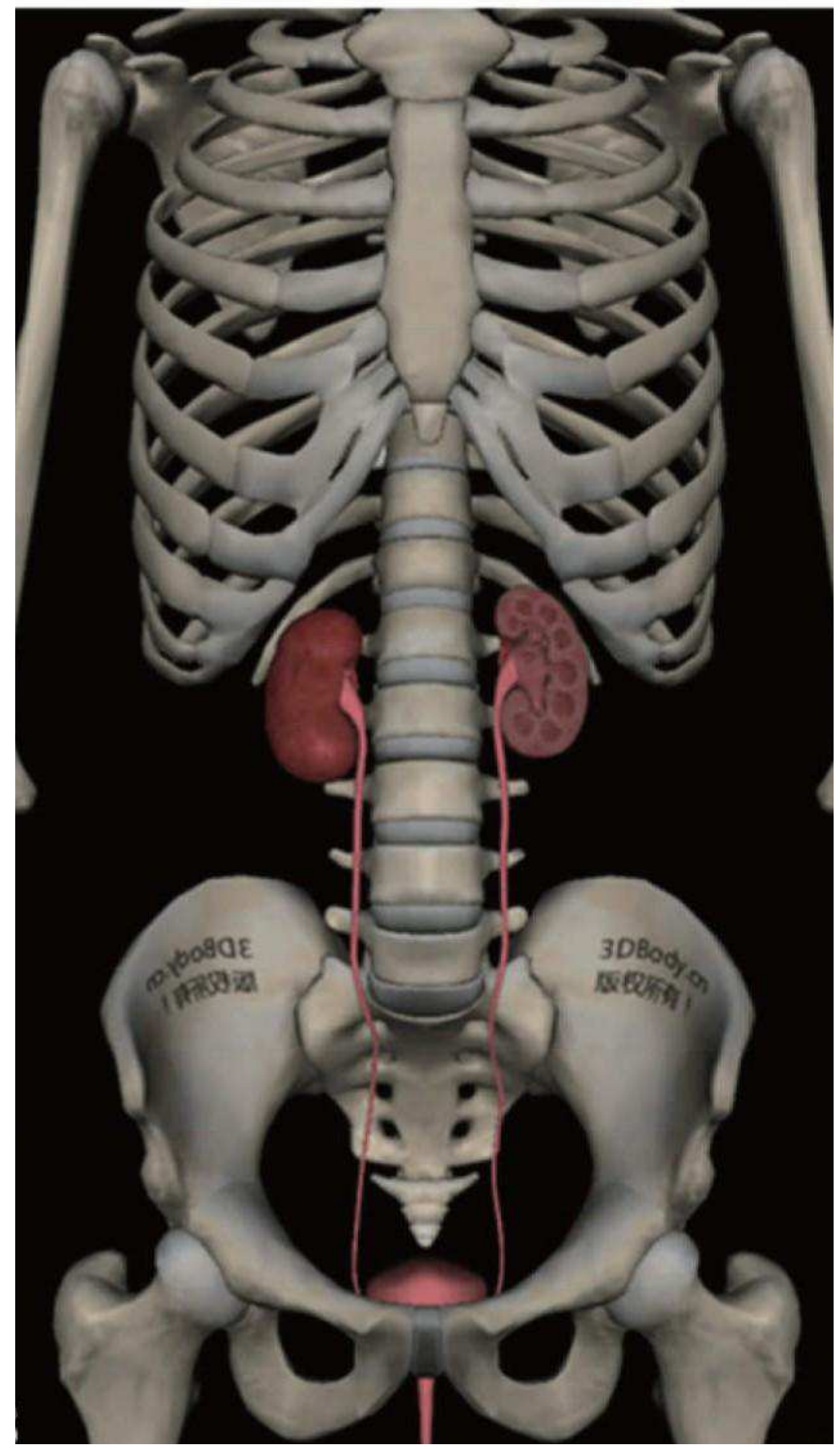

Fig. 5. Screenshot of 3DBody-based teaching plan for the urinary system chapter 


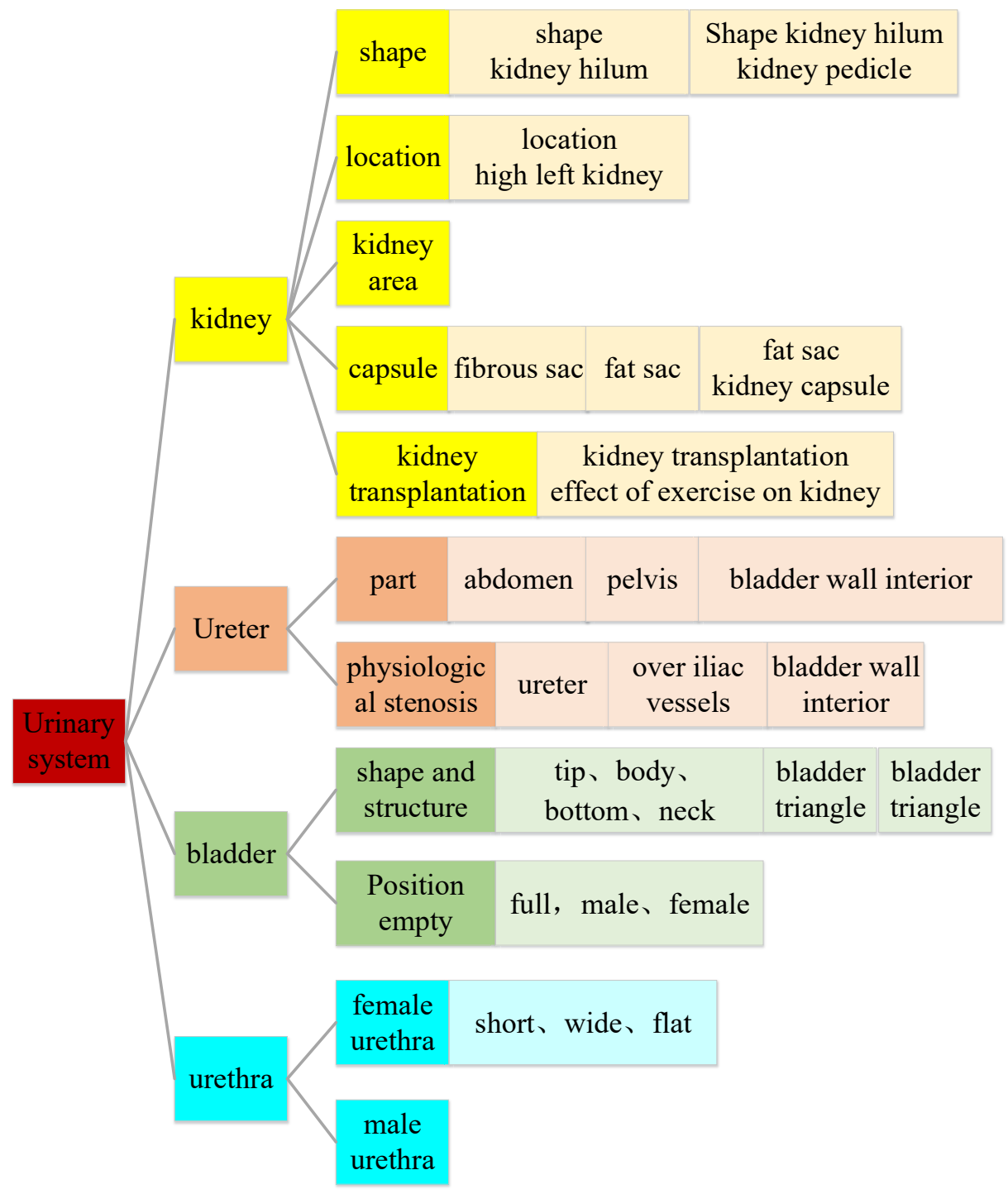

Fig. 6. Mind map of the urinary system chapter

Fig. 7 presents the teaching process design of the 3DBody-based mind map teaching mode for Sports Anatomy. 

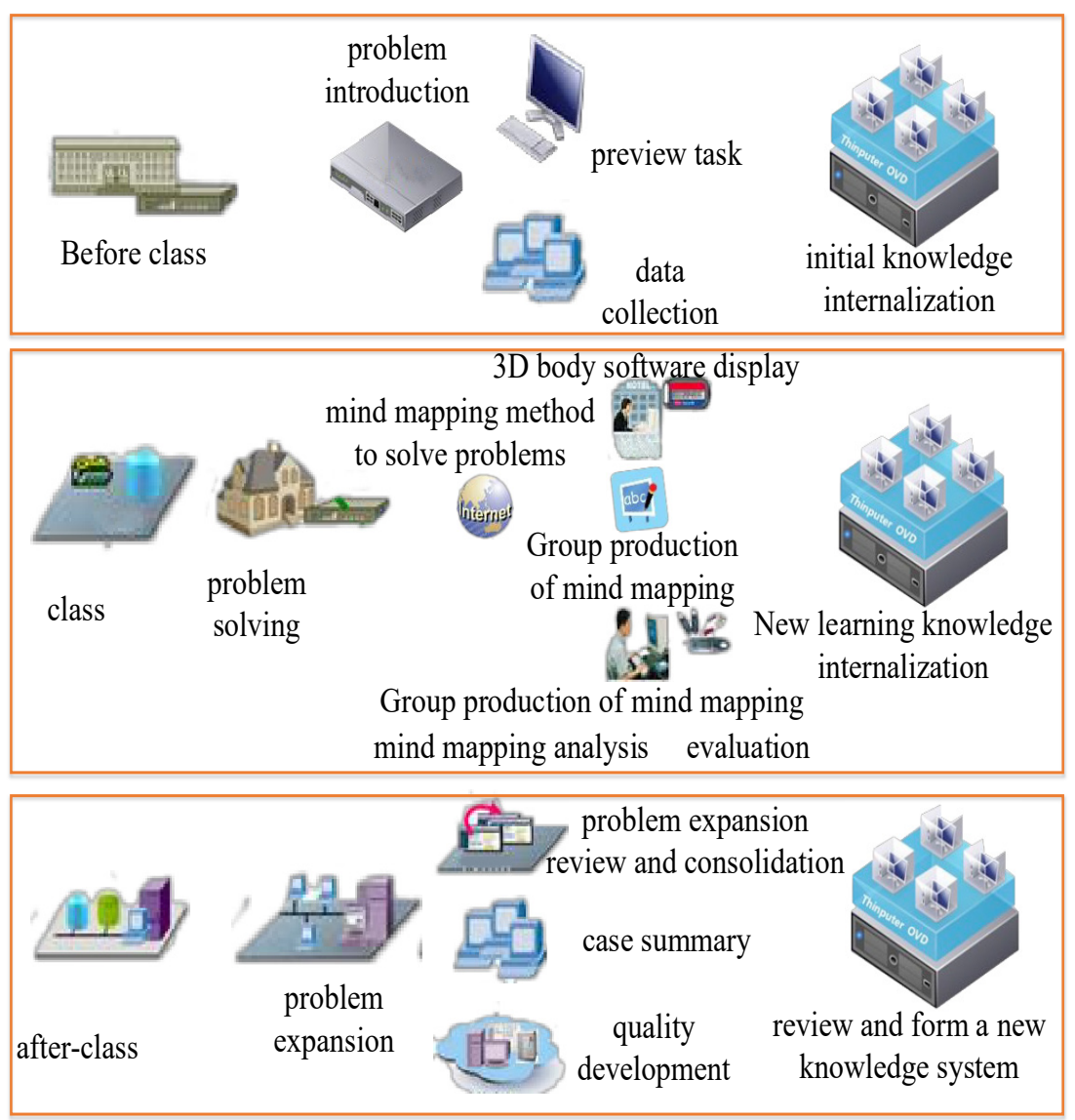

Fig. 7. Teaching process design

The process aimed at designing a pre-class task list for relevant course content in the pre-class teaching link. The list was then distributed to students through a network teaching platform. Students were required to know the chapter content and collect relevant materials to guide their original knowledge system. An in-class teaching link was designated to solve problems. For the specific content, the teacher designed relevant questions and displayed the cases and contents of sports anatomy through the 3DBody. Then, the students were guided to conduct a speculative and conclusive analysis. Subsequently, the teacher introduced the mind map method and required students to draw the mind maps and discuss in groups. These steps aim to guide students in adopting the mind map and combining the 3DBody software toward establish a new knowledge system of anatomy. An after-class link was later designated to extend questions. A network teaching platform was applied to consolidate the contents and summarize the cases. Moreover, quality promotion content was designed to guide students in further deducing a new comprehensive knowledge system. 


\section{$4 \quad$ Teaching Example and Teaching Effect}

\subsection{Teaching example}

This study randomly chose two freshman classes as the experimental classes in a sports university, where the author works. The experimental classes were categorized into experimental and control classes with 50 students per class. The 3DBody-based mind map teaching method was applied for the experimental class to reform the teaching, whereas traditional multimedia PPT teaching mode was used for the control class to verify the effect. The experimental period was from October to December 2018.

\subsection{Teaching effect}

After the course ended, the teaching effects of the experimental class and the control class were analyzed. Students' assessments of the teaching effects in both experimental and control classes were collected through anonymous questionnaires. The students' satisfaction evaluation for teaching effects was surveyed from learning interest, learning initiative contrast, autonomous learning time, and subsequent influence. Table 1 presents the survey data. Table 2 shows the teaching effect evaluation of the experimental class.

Table 1. Teaching satisfaction survey $(\%)$

\begin{tabular}{|l|c|c|c|c|}
\hline \multicolumn{1}{|c|}{ Group } & Very satisfied & Satisfied & General & Dissatisfied \\
\hline Experimental group & 38 & 12 & 0 & 0 \\
\hline Control group & 16 & 18 & 8 & 7 \\
\hline
\end{tabular}

Table 2. Teaching effect evaluation $(\mathrm{N}=50)$

\begin{tabular}{|l|c|c|c|c|}
\hline \multicolumn{1}{|c|}{ Survey content } & Very agree & Agree & General & Disagree \\
\hline Strengthen knowledge mastery (\%) & 46.09 & 29.13 & 24.78 & 0 \\
\hline $\begin{array}{l}\text { Make the relation between teachers and students } \\
\text { harmonious (\%) }\end{array}$ & 60.43 & 28.48 & 11.09 & 0 \\
\hline Motivate learning interest (\%) & 45.13 & 47.17 & 3.7 & 0 \\
\hline Necessary to continue use (\%) & 50.43 & 37.83 & 11.74 & 0 \\
\hline
\end{tabular}

As seen from Table 1 and Fig. 8, the effects of Sports Anatomy teaching on the experimental and control classes are evidently different from each other. The students in the experimental class thought highly of the learning effect of the course, and their learning satisfaction was considerably higher than that of the control class. This feedback indicates that the mode proposed in this study has a certain advantage to enhance teaching satisfaction in the course. According to Table 2, $85 \%$ of the students claimed that this mode enhanced their mastery of anatomical knowledge. $89 \%$ of the students thought that a harmonious relationship exists between the teacher and students in such a teaching mode. $96 \%$ of the students held that this mode stimulates their interest in learning. By contrast, the learning initiative of the control class was low. The teaching 
defects of traditional teaching method undoubtedly triggered a negative effect on students. The survey result confirms that the research mode teaching process could stimulate their learning interest and enhance the harmonious relationship between the teacher and students. Nearly $80 \%$ of the students hoped to continue learning with the proposed teaching mode, thus implying that this method conforms to the students' learning style, promotes learning exchange in the teaching link, mobilizes their interest in active learning, stimulates their initiative for further learning, and reaches the teaching objective.

Upon further analysis, the combination of mind mapping and the 3DBody software has shown clear advantages in Sports Anatomy teaching. The mind map employs rich colors and lines as well as clear patterns to summarize key knowledge points, thus helping students in effectively associating and remembering information. The 3D structure presented by the 3DBody software turns dull texts into concrete and vivid animations and pictures, thereby granting the students a visual understanding of the structures of each organ and enabling them to establish the connection from the local to the global perspective. As such, students enhance their mastery of anatomical knowledge and heighten their interest in learning. The combination of the mind map learning method and the 3DBody software mobilizes the students' learning initiative, enhances exchange among students and communication between teachers and students, and benefits teachers as well as students. However, the application of this teaching mode remains at its early stage. The students' learning interest may decline after this teaching mode has been implemented for an extended period. This teaching method attracts students; thus, the students' active learning driven by their sense of responsibility should be cultivated to achieve the optimal learning effect. The new reform research on anatomy teaching modes requires close attention toward enhancing teaching quality.

\section{Conclusion}

In Sports Anatomy teaching research, the mind map analysis method can guide students in collating logic relationships in anatomical knowledge and clearly determining the key knowledge points to enable convenient recall of information. The 3DBody anatomy software transforms dull texts on anatomy into concrete and vivid animations and pictures, thereby granting the students a visual understanding of the structures of each organ. The mind map analysis method and the 3Dbody anatomy software were combined in this study to carry out applied research on teaching mode reforms in Sports Anatomy. The results show that this teaching mode does not merely promote the students' learning interest and mobilize their learning initiative. It also enhances the exchange among students and the communication between teachers and students while benefiting both teachers and students. Finally, this study provides a feasible development direction for Sports Anatomy teaching reform. 


\section{Acknowledgement}

A Project Supported by Ordinary Colleges Teaching Reform and Research Project of Hunan Province. (2018-842).

\section{$7 \quad$ References}

[1] Carter, A.G., Creedy, D.K., Sidebotham, M. Efficacy of teaching methods used to develop critical thinking in nursing and midwifery undergraduate students: A systematic review of the literature. Nurse Education Today, 2016, vol. 40, pp. 209-218. https://doi.org/10.1 016/j.nedt.2016.03.010

[2] Davies, M. Concept mapping, mind mapping and argument mapping: what are the differences and do they matter?. Higher Education, 2011, vol. 62(3), pp. 279-301. https://doi.org/10.1007/s10734-010-9387-6

[3] Park, S., Jang, J.Y., Chen, Y.C., et al. Is Pedagogical Content Knowledge (PCK) Necessary for Reformed Science Teaching?: Evidence from an Empirical Study. Research in Science Education, 2011, vol. 41(2), pp. 245-260. https://doi.org/10.1007/s11165-0099163-8

[4] Abi-El-Mona, I., Adb-El-Khalick, F. The Influence of Mind Mapping on Eighth Graders' Science Achievement. School Science \& Mathematics, 2010, vol. 108(7), pp. 298-312. https://doi.org/10.1111/j.1949-8594.2008.tb17843.x

[5] Hu, Y., Huang, L. The Role of Mind Mapping in Improving the Learning Self-efficacy of Higher Vocational Students. Course Education Research, 2013, vol. 19, pp. 176-176.

[6] Kalyanasundaram, M., Abraham, S.B., Ramachandran, D., et al. Effectiveness of Mind Mapping Technique in Information Retrieval Among Medical College Students in Puducherry-A Pilot Study. Indian Journal of Community Medicine Official Publication of Indian Association of Preventive \& Social Medicine, 2017, vol. 42(1), pp. 19-23. https://doi.org/10.4103/0970-0218.199793

[7] Woradechjumroen, D. Mind map learning for advanced engineering study: case study in system dynamics. IOP Conference Series Materials Science and Engineering, 2018, pp. 297. https://doi.org/10.1088/1757-899x/297/1/012054

[8] Ren, Y.J., Jiang, X., \& Tang, S.Y. 3dbody software experimental platform for course of sports anatomy. International Journal of Emerging Technologies in Learning, 2017, vol. 12(9), pp. 4-16. https://doi.org/10.3991/ijet.v12i09.7482

[9] Lai, Y.P., He, L., Fang, Y., et al. Application of Virtual Anatomy Software 3body.7.0 in Human Anatomy Learning. Diet Health, 2016, vol. 3(10), pp. 26.

[10] Brenton, H., Hernandez, J., Bello, F., et al. Using multimedia and Web3D to enhance anatomy teaching. Computers \& Education, 2007, vol. 49(1), pp. 32-53. https://doi.org/10.10 16/j.compedu.2005.06.005

[11] Favier, J., Pinelli, A., Piomelli, U. Control of the separated flow around an airfoil using a wavy leading edge inspired by humpback whale flippers. Comptes Rendus Mecanique, 2012, vol. 340(1-2), pp. 107-114. https://doi.org/10.1016/j.crme.2011.11.004

[12] Burns, A., Freeman, D., Edwards, E. Theorizing and Studying the Language-Teaching Mind: Mapping Research on Language Teacher Cognition. Modern Language Journal, 2015, vol. 99(3), pp. 585-601. https://doi.org/10.1111/modl.12245 


\section{Authors}

Yujia Ren is an associate professor in the Physical Education Institute, Hunan First Normal University, Changsha 410205, Hunan, China (renyujia@163.com).

Xia Jiang (Corresponding Author) is an associate chief physician in the Wuhan Sports University, Wuhan 430079, China (274541977@qq.com).

Article submitted 2019-03-30. Resubmitted 2019-04-30. Final acceptance 2019-05-01. Final version published as submitted by the authors. 